\title{
Pharmacogenetics of human ABC transporter ABCC11: new insights into apocrine gland growth and metabolite secretion
}

\author{
Toshihisa Ishikawa ${ }^{1,2}$ *, Yu Toyoda ${ }^{1,3}$, Koh-ichiro Yoshiura ${ }^{4}$ and Norio Niikawa ${ }^{4,5}$ \\ 1 Graduate School of Bioscience and Biotechnology, Tokyo Institute of Technology, Yokohama, Japan \\ ${ }^{2}$ Omics Science Center, RIKEN Yokohama Institute, Yokohama, Japan \\ ${ }^{3}$ Department of Pharmacy, The University of Tokyo Hospital, Faculty of Medicine, The University of Tokyo, Tokyo, Japan \\ ${ }^{4}$ Department of Human Genetics, Nagasaki University Graduate School of Biomedical Sciences, Nagasaki, Japan \\ ${ }^{5}$ The Research Institute of Personalized Health Sciences, Health Sciences University of Hokkaido, Ishikari-Tobetsu, Japan
}

\section{Edited by:}

José A. Agúndez, University of

Extremadura, Spain

Reviewed by:

Martin Lennard, University of Sheffield, UK

Juergen Reichardt, James Cook

University, Australia

\section{*Correspondence:}

Toshihisa Ishikawa, Omics Science Center, RIKEN Yokohama Institute, 1-7-22 Suehiro-cho, Tsurumi-ku, Yokohama 230-0045, Japan. e-mail: toshi-@gsc.riken.jp
Cell secretion is an important physiological process that ensures smooth metabolic activities and tissue repair as well as growth and immunological functions in the body. Apocrine secretion occurs when the secretory process is accomplished with a partial loss of cell cytoplasm. The secretory materials are contained within secretory vesicles and are released during secretion as cytoplasmic fragments into the glandular lumen or interstitial space. The recent finding that the non-synonymous single nucleotide polymorphisms (SNP) 538G > A (rs17822931; Gly180Arg) in the ABCC11 gene determines the type of earwax in humans has shed light on the novel function of this ABC (ATP-binding cassette) transporter in apocrine glands. The wild-type (Gly180) of ABCC11 is associated with wet-type earwax, axillary osmidrosis, and colostrum secretion from the mammary gland as well as the potential risk of mastopathy. Furthermore, the SNP $(538 \mathrm{G}>\mathrm{A})$ in the $A B C C 11$ gene is suggested to be a clinical biomarker for the prediction of chemotherapeutic efficacy. The aim of this review article is to provide an overview on the discovery and characterization of genetic polymorphisms in the human $A B C C 11$ gene and to explain the impact of $A B C C 11538 \mathrm{G}>\mathrm{A}$ on the apocrine phenotype as well as the anthropological aspect of this SNP in the ABCC11 gene and patients' response to nucleoside-based chemotherapy.

Keywords: apocrine gland, earwax, axillary osmidrosis, breast cancer, mastopathy, 5-fluorouracil, tamoxifen

\section{INTRODUCTION}

ATP-binding cassette $(\mathrm{ABC})$ proteins form one of the largest protein families encoded in the human genome (Dean et al., 2001; Holland et al., 2003). Hitherto more than 48 human ABC protein genes have been identified and sequenced (Klein et al., 1999). It has been reported that mutations of $\mathrm{ABC}$ protein genes are causative of several genetic disorders in humans (Dean et al., 2001). Many of the human $\mathrm{ABC}$ proteins are involved in membrane transport of drugs, xenobiotics, endogenous substances, or ions, thereby exhibiting a wide spectrum of biological functions (Schinkel and Jonker, 2003). Based on the arrangement of molecular structure components, i.e., nucleotide binding domains and topologies of transmembrane domains, the hitherto reported human $\mathrm{ABC}$ proteins have been classified into seven different sub-families (A to G; Klein et al., 1999; Borst and Elferink, 2002; Ishikawa, 2003).

In 2001, three research groups independently cloned two novel $\mathrm{ABC}$ transporters named $\mathrm{ABCC} 11$ and $\mathrm{ABCC} 12$ from the $\mathrm{CDNA}$ library of human adult liver (Bera et al., 2001; Tammur et al., 2001; Yabuuchi et al., 2001). These two genes have been found to be located on human chromosome 16q12.1 in a tail-to-head orientation with a separation distance of about $20 \mathrm{~kb}$ (Figure 1). The predicted amino acid sequences of both gene products show a high similarity to those of $\mathrm{ABCC} 4$ and $\mathrm{ABCC} 5$, which suggests that they have the typical structure of "full" $\mathrm{ABC}$ transporters with
12 transmembrane helixes and two ABCs. Interestingly, there is no putative mouse or rat orthologous gene corresponding to human $A B C C 11$ (Shimizu et al., 2003), which indicates that $A B C C 11$ is not an orthologous gene but rather a paralogous gene generated by gene duplication in the human genome. In contrast, $A B C C 12$ and its orthologous genes are found in several different species including humans, primates, and rodents (Shimizu et al., 2003; Ono et al., 2007). Transcript analyses suggest that human ABCC11 mRNA is ubiquitously expressed in human adult and fetal tissues (Tammur et al., 2001; Yabuuchi et al., 2001). High levels of ABCC11 mRNA were observed in breast cancer tissues (Bera et al., 2001; Yabuuchi et al., 2001). Table 1 summarizes major findings in the research of the $A B C C 11$ gene.

When transfected exogenously, the ABCC11 wild-type (WT) protein was localized in the apical membrane of Madin-Darby canine kidney cells strain II (MDCK II cells; Bortfeld et al., 2006). The substrate specificity of ABCC11 WT was characterized in more detail by an in vitro transport assay with plasma membrane vesicles prepared from pig LLC-PK1 cells transfected with an ABCC11 WT expression vector (Chen et al., 2005). The results of this assay demonstrated that ABCC11 WT is able to transport a variety of lipophilic anions including cyclic nucleotides, glutathione conjugates such as leukotriene $\mathrm{C}_{4}\left(\mathrm{LTC}_{4}\right)$ and S(2,4-dinitrophenyl)-glutathione (DNP-SG), steroid sulfates such 

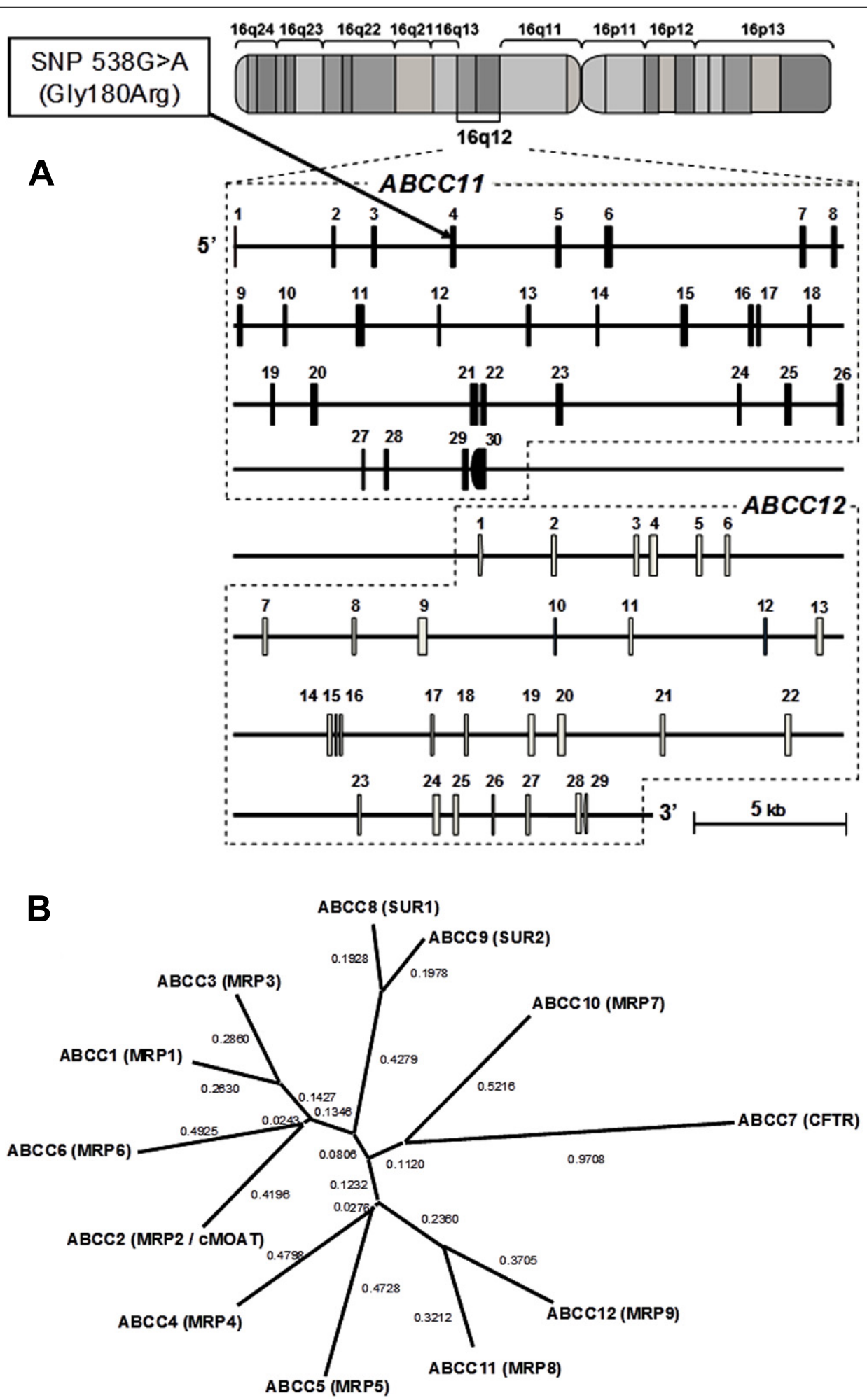

FIGURE 1 | Schematic illustration of the genomic structures of $A B C C 11$ and $A B C C 12$ genes on human chromosome 16q12.1. (A) The cytogenetic location of the $A B C C 11$ gene as well as the structures of exons and introns were analyzed by BLAST searches on the human genome. $A$ non-synonymous SNP: $538 \mathrm{G}>\mathrm{A}$ (Gly180Arg), an earwax determinant, is located in exon 4. (B) Phylogenetic tree of the ABCC subfamily including CFTR, SUR1, SUR2, and MRPs. The phylogenetic tree was modified from Toyoda et al. (2008). The phylogenetic relationships among members of the " $C$ " sub-family of human $A B C$ transporters were calculated by using the distance-based neighbor-joining methods (Saitou and Nei, 1987). 
Table 1 | Historical overview on identification of the $A B C C 11$ gene and its function.

\begin{tabular}{|c|c|c|}
\hline Year & Scientific progress & Reference \\
\hline \multirow[t]{2}{*}{2001} & Discovery of human $A B C C 11$ (MRP8) gene & Bera etal. (2001), Tammur et al. (2001), \\
\hline & & Yabuuchi et al. (2001) \\
\hline 2003 & Characterization of ABCC11 as a cyclic nucleotide efflux pump & Guo et al. (2003) \\
\hline 2005 & In vitro characterization of substrate selectivity of ABCC11 & Chen et al. (2005) \\
\hline 2006 & Characterization as an apical efflux pump for steroid sulfates in CNS & Bortfeld et al. (2006) \\
\hline 2006 & Identification of $A B C C 11$ SNP c.538G > A as the determinant of human earwax type & Yoshiura et al. (2006) \\
\hline 2007 & Association between the degrees of apocrine colostrum secretion and $A B C C 11$ genotype & Miura et al. (2007) \\
\hline 2008 & Involvement of $\mathrm{ABCC} 11$ in 5-fluorouracil resistance in lung cancer cell line & Oguri etal. (2007) \\
\hline 2008 & Regulation of ABCC11 expression by estrogen in MCF7 cells & Honorat et al. (2008) \\
\hline 2009 & Discovery of ubiquitination and proteasomal degradation of SNP c.538G > A variant & Toyoda et al. (2009) \\
\hline \multirow[t]{2}{*}{2009} & Association between axillary osmidrosis and ABCC11 wild-type & Nakano etal. (2009), Toyoda etal. (2009), \\
\hline & & Inoue et al. (2010) \\
\hline 2009 & Japanese map of the earwax gene frequency: a nationwide collaborative study & Super Science High School Consortium (2009) \\
\hline 2010 & Association between breast cancer risk and $A B C C 11$ wild-type in Japanese women & Ota etal. (2010), Toyoda and Ishikawa (2010) \\
\hline 2010 & Involvement of $\mathrm{ABCC} 11$ in pemetrexed resistance in lung cancer & Uemura et al. (2010) \\
\hline 2011 & No association between breast cancer risk and $A B C C 11$ wild-type in European women & Beesley etal. (2011), Lang etal. (2011) \\
\hline 2011 & Down-regulation of $\mathrm{ABCC} 11$ protein in human breast cancer & Sosonkina etal. (2011) \\
\hline
\end{tabular}

as estrone 3-sulfate $\left(\mathrm{E}_{1} 3 \mathrm{~S}\right)$ and dehydroepiandrosterone 3-sulfate (DHEAS), glucuronides such as estradiol 17- $\beta$-D-glucuronide $\left(\mathrm{E}_{2} 17 \beta \mathrm{G}\right)$, the monoanionic bile acids glycocholate and taurocholate, as well as folic acid and its analog methotrexate (MTX; Chen etal., 2005; Bortfeld etal., 2006). Chemical structures of these compounds are presented in Figure A1 in Appendix. While ABCC11 transports a variety of organic anions, endogenous natural substrates for this transporter have not yet been identified.

\section{GENETIC POLYMORPHISMS AND PHYSIOLOGICAL FUNCTION OF ABCC11}

To date, more than 10 non-synonymous single-nucleotide polymorphisms (SNPs) have been reported in the human ABCC11 gene (Figure 2). Among those SNPs, one SNP (rs17822931; 538G > A, Gly180Arg) determines the human earwax type (Yoshiura et al., 2006). Interestingly, this SNP (538G > A) exhibits wide ethnic differences in allelic frequency (Table 2). In Mongoloid populations in Asia, the frequency of the 538A allele is predominantly high, whereas the frequency of this allele is low among Caucasians and Africans (Yoshiura et al., 2006; Toyoda et al., 2008; Figure 3A). The frequency of the 538A allele exhibits a north-south and eastwest downward geographical gradient with the highest peak in Korea. It is suggested that the 538A allele arose in northeast Asia and thereafter spread throughout the world (Yoshiura et al., 2006), apparently reflecting the inter-continental migration of Homo sapiens (Figure 3B). A similar geographical gradient was also observed in the frequency of the 2677G (Ala893) allele of the ABCB1 (P-glycoprotein/MDR1) gene (Sakurai et al., 2007). In this regard, anthropological aspects of SNP $538 \mathrm{G}>\mathrm{A}$ in the $A B C C 11$ gene are described in the following section.

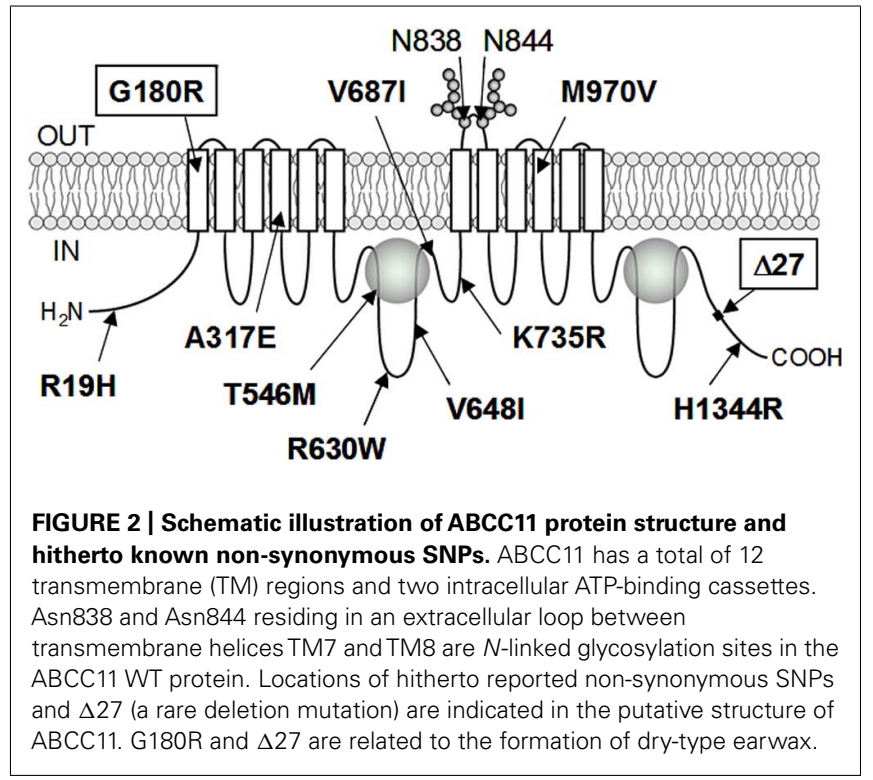

Earwax (cerumen) is a secretory product of the ceruminous apocrine glands, which can be classified into two phenotypes in humans, wet (sticky) and dry. The dry-type is most commonly found within the Asian population, especially among Koreans, Japanese, and Chinese; whereas the wet-type is the dominant phenotype for many Africans and Caucasians. The 538A/A genotype gives the dry phenotype, whereas both the 538G/A and G/G genotypes give the wet phenotype. This relationship is consistent with observations that earwax type is a Mendelian trait and that the wet phenotype is dominant to the dry one. 
Table 2 | Frequencies of $A B C C 11$ genotypes and allele c.538A among different ethnic groups.

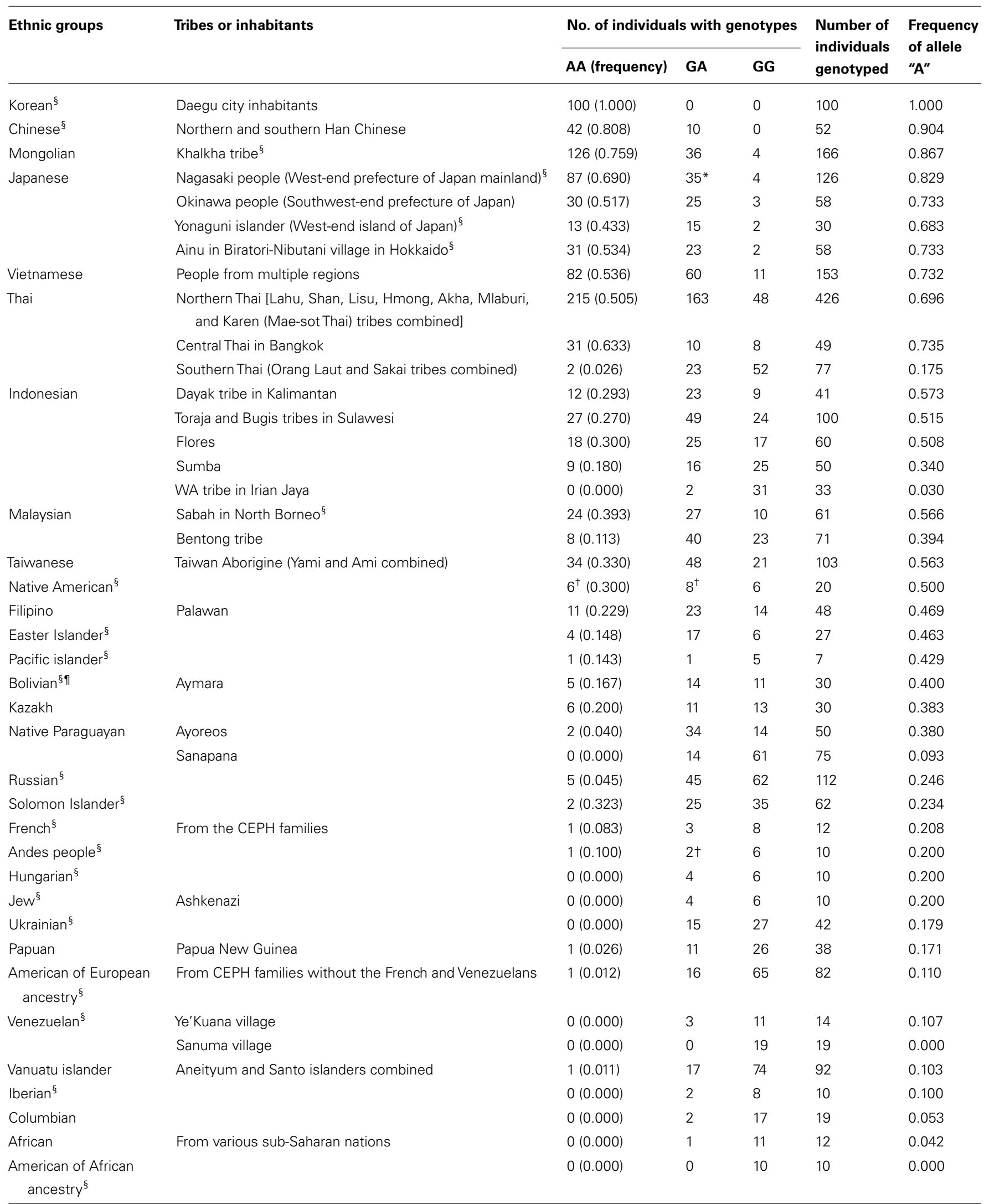

Data are from Yoshiura etal. (2006). ${ }^{\S}$ Examined for a 27-bp deletion (A27) in ABCC11; * One exceptional case of dry cerumen who has the deletion; ${ }^{\dagger}$ One each case of the deletion; "Nine cases of the deletion. 


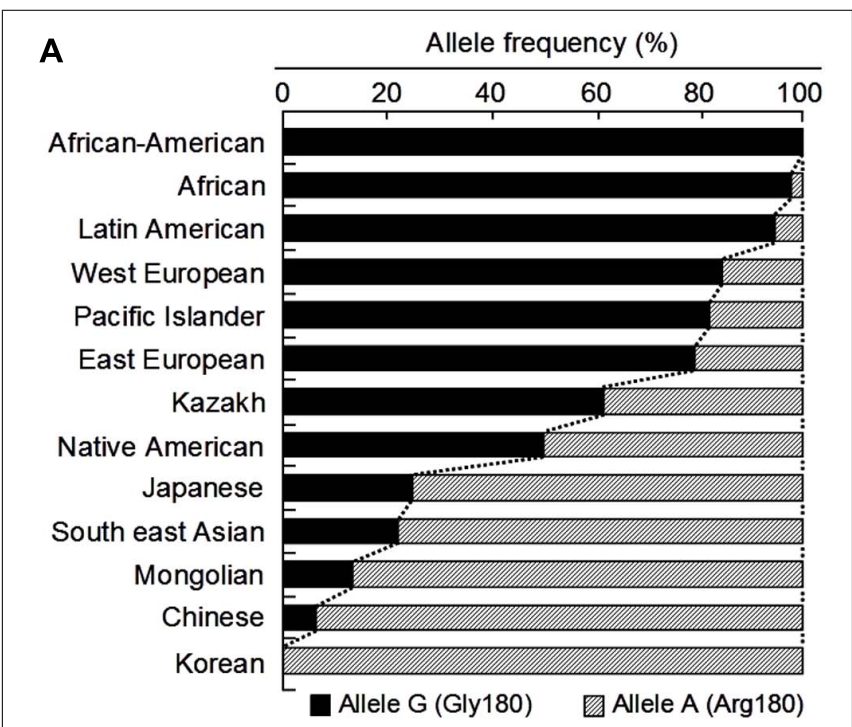

B

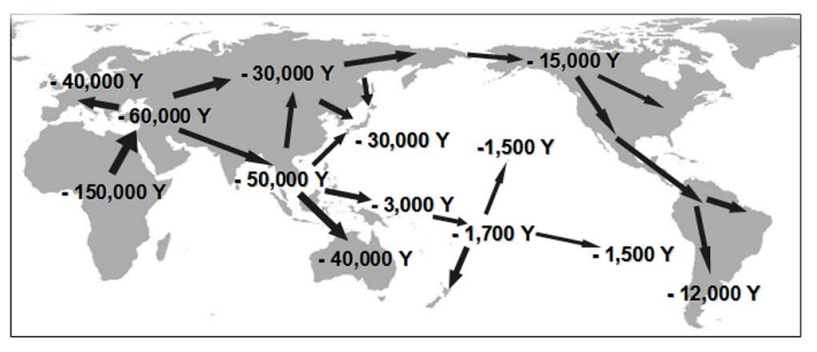

FIGURE 3 | The allele frequencies of the wild-type (WT; Gly180) and 538G > A (Arg180) variant of human ABCC11 among different ethnic populations (A) and inter-continental migration of Homo sapiens (B). Data are from Yoshiura etal. (2006) and Toyoda et al. (2008).

Immunohistochemical studies with cerumen gland-containing tissue specimens revealed that the ABCC11 WT protein with Gly180 was expressed in the cerumen gland (Toyoda et al., 2009). The cerumen gland is one of the apocrine glands. In addition to their presence in the external auditory canal, apocrine glands can be found in the axillary region and breast, whose physical characteristics also are concerned with apocrine glands. In fact, there is a positive association among the wet earwax type, axillary osmidrosis (Yoo et al., 2006), and colostrum secretion from the breast (Miura et al., 2007).

\section{ANTHROPOLOGICAL ASPECTS OF ALLELES 538G AND 538A}

It is generally accepted that, since they migrated out-of-Africa, humans spread all over the world with great diversity (CavalliSforza, 2005). Whilst the routes of migration followed by the ancient Mongoloid people remain obscure, two different routes have been proposed (Figure 3B). After branching from a main stream common to the ancient Caucasoids 150,000-60,000 years ago (Nei, 1982), the ancient Mongoloids migrated to Southern Asia. It is assumed that one branch remained there or further migrated more south-eastwardly through the so-called Sundaland and Sahuland, and finally reached the Australian continent 50,000-46,000 years ago (Bowler et al., 2003). The last wave of migration of people to the Southern Pacific islands took place more recently, 3,000-1,500 years ago. On the other hand, another branch migrated northward and reached an area around Lake Bikal of Siberia along the Altai mountains. Alternatively, a branch of the ancient Mongoloids might have directly migrated to Siberia from the common stream or migrated from South East Asia toward North East Asia (The HUGO Pan-Asian SNP Consortium, 2009). As an expansion of the last glaciation occurred 30,000-15,000 years ago, small tribes of the ancient Northern Mongoloids may have long been isolated by the glaciers.

As described above, wet/dry types of earwax are determined by the SNP c.538G > A in the ABCC11 gene; G/A and G/G genotypes give the wet-type and A/A the dry-type. There is a hypothesis that a c.538G (wet-type) $\rightarrow$ c.538A (dry-type) mutation may have occurred some 40,000 years ago in a tribe of the ancient Northern Mongoloids (Ohashi et al., 2011). Subsequent spreading of the dry-type among the Mongoloids may be explained by a certain selective advantage of the mutation (Matsunaga, 1962), or dry cerumen might have been evolutionally neutral, which would have led to its spread as an attribute of genetic drift. Based on the geographical gradient distribution of the 538A allele with a peak in East Asia, especially in Northern China and Korea, one might assume that the $\mathrm{c} .538 \mathrm{G} \rightarrow \mathrm{c} .538 \mathrm{~A}$ mutation arose somewhere in Siberia. The north-south downward gradient of the $538 \mathrm{G}$ allele from Northern China toward Japan and Southern Asia might reflect the Ancient Northern Mongoloid migrations. Similarly, the east-west gradient from Siberia toward Europe (Spitsyn and Afanasèva, 1989) is partly the consequence of Mongolian migration, especially as their invasions pushed westward from about A.D. 500 until A.D. 1500. The situation is much like the frequency of type $\mathrm{B}$ for the $\mathrm{ABO}$ blood group, which is high in Asia $(>25 \%)$ and low $(<10 \%)$ in Europe (Roychoudhury and Nei, 1988). Similar geographic distribution and ethnic differences are known for the $A L D H 2$ gene, one of the major determinants for alcohol sensitivity (Goedde et al., 1992; Luo et al., 2009).

The relatively high frequency of the 538A allele among presentday Native Americans suggests that their ancestors may have undertaken long journeys from Siberia through the Bering landbridge (Beringia) to the American continent during the past 15,000 years (Horai et al., 1993; Bonatto and Salzano, 1997; Tokunaga et al., 2001; Dillehay, 2003). Based on recent craniometric studies of skeletons from archeological remains in the Baja California peninsula, however, it has also been postulated that an earlier migration wave from that via the northern route might have occurred from islands of south-eastern Asia by an ancestor common to both Palaeoamericans and Australians around 40,00012,000 years ago (Gonzáles-José et al., 2003). Furthermore, the allelic data for South Americans revealing the 538A allele frequency of 0.400 in Bolivia, 0.200 in the Andes region, $0.093-0.380$ in Paraguay, 0.053 in Colombia, and 0.000 in Venezuela rather favors a hypothesis of an ancient migration through a "pacific coast road" along the Andes mountain range.

\section{ROUTES OF THE JAPANESE POPULATION}

The Japanese population is considered to have a dual structure comprising descendants of mixtures between the ancient "Jomon" and "Yayoi" populations. The term "Jomon" is derived 
from characteristic twisted cord striations or marks on earthenware used during a prehistoric time $(13,000-3,000$ years ago) in Japan. As it has been reported that the Jomon had occupied various areas of Japan prior to the Yayoi's appearance, they apparently were either assimilated or rather moved away from the Yayoi (Iizuka and Nakahashi, 2002; Temple et al., 2008; Temple, 2010). It is hypothesized that the dry earwax type was introduced by the Yayoi people to the Jomon population, where the wet-type had been predominant.

Since the admixture of the two Jomon and Yayoi populations is still not complete in Japan even now, the $538 \mathrm{G}$ allele frequency is higher in the rather remote areas where the Jomon moved away from the Yayoi's peopling route within the Japanese islands. The Ainu-Japanese people living in a Japanese northern island "Hokkaido" are aboriginal inhabitants of Japan. Based on morphological and mitochondrial DNA polymorphism studies, it has been hypothesized that both the Ainu- and the Okinawa-Japanese living in a Japanese southern island "Okinawa" are descendants of the ancient native Japanese, "Jomon" people (Horai et al., 1991). Molecular studies demonstrated that Ainu-Japanese still retain a certain degree of their own genetic uniqueness among surrounding populations, and exhibit considerable genetic distance from other East Asian populations (Tokunaga et al., 2001; Tajima et al., 2004). As far as wet-type of earwax and the $538 \mathrm{G}$ allele frequency are concerned, the Ainu- and Okinawa-Japanese people are not the direct descendants "Yayoi" from the Ancient Northern Mongoloids of Siberian origin.

To analyze the nationwide allele frequency, the Super Science High School (SSH) consortium collected a total of 1963 fingernail samples of pupils/students from at least one high school/university in every prefecture in Japan (Super Science High School Consortium, 2009). Although the 538G allele frequency varied among the 47 prefectures, the Gifu/Kyoto and Okinawa prefectures showed the lowest and highest values for the $538 \mathrm{G}$ allele, respectively. Other areas with low frequencies of the 538G allele included Northeastern Kyushu, Northern Shikoku, and Kinki districts, showing a belt-like zone, whereas those with high frequencies of the $538 \mathrm{G}$ allele next to Okinawa were the Southwestern Kyushu, Hiroshima prefecture, and Tohoku districts. Those observations strongly suggest that the admixture of "Jomon" and "Yayoi" populations is still not complete in Japan.

\section{STRONG ASSOCIATION BETWEEN AXILLARY OSMIDROSIS AND THE GENOTYPE OF ABCC11 538G > A}

Today in Japan, axillary osmidrosis is recognized as a disease that is covered by the national health insurance system. Axillary osmidrosis, which is exemplified by unpleasant odors, sweating and staining of clothes, is often perceived, especially by young women, as a distressing and troublesome problem (Wu et al., 1994). Axillary osmidrosis is a chronic skin condition characterized by an excessive, axillary malodor resulting from apocrine gland dysfunction (Hess et al., 2008). Certain people display an excessive fear, aversion or psychological hypersensitivity to unpleasant smells or odors. They tend to opt for aggressive surgical treatments and are sometimes categorized as having osmophobia. Interestingly, an association between wet-type earwax and axillary osmidrosis had already been recognized more than half a century ago (Matsunaga,
Table 3 | Association of ABCC11 genotype with earwax type and axillary osmidrosis in Japanese subjects.

\begin{tabular}{llllll} 
Earwax type & \multicolumn{2}{l}{ Genotype at $\boldsymbol{A B C C 1 1} \mathbf{5 3 8 G} \boldsymbol{>} \mathbf{A}$} & $\begin{array}{l}\text { Axillary osmidrosis } \\
\text { patients }\end{array}$ \\
\cline { 3 - 5 } & G/G & G/A & A/A & \\
\hline Dry & 262 & 0 & 0 & 262 & 0 \\
Wet & 300 & 23 & 277 & 0 & 182
\end{tabular}

Data are calculated from Inoue etal. (2010) and Nakano etal. (2009).

1962). Hence, the wet-type of earwax has frequently been used as one of diagnostic criteria and characteristics in the clinic. This relationship, however, had only been based on the observations of those two respective phenotypes. Therefore, there has been a need for objective evidence for diagnosis of axillary osmidrosis to prevent unnecessary treatments for such patients.

Recently, it has been reported that the ABCC11 WT allele is intimately associated with axillary osmidrosis as well as the wet-type of earwax (Table 3). Several studies have already concluded that the genotypes at ABCC11 538G > A would be useful biomarkers for the diagnosis of axillary osmidrosis (Nakano et al., 2009; Toyoda et al., 2009; Inoue et al., 2010; Martin et al., 2010). Therefore, it is suggested that genotyping of the ABCC11 gene would provide an accurate and practical criterion for guidance of appropriate treatment and psychological management of patients (Toyoda et al., 2009; Inoue et al., 2010; Ishikawa and Hayashizaki, 2012). Rapid genotyping of the $A B C C 11$ gene is briefly described in Appendix.

Sweat produced by the axillary apocrine glands is odorless. Secretions from the apocrine glands, however, can be converted to odoriferous compounds by bacteria (Corynebacteria), which results in the formation of the unique "human axillary odor" (Shehadeh and Kligman, 1963). Axillary osmidrosis patients (538G/G homozygote or G/A heterozygote) were observed to have significantly more numerous and larger-sized axillary apocrine glands as compared with those in subjects carrying the A/A homozygote. Indeed, the $538 \mathrm{G}$ allele in the $A B C C 11$ gene is associated with axillary osmidrosis (Nakano et al., 2009; Toyoda et al., 2009; Inoue et al., 2010; Martin et al., 2010), and ABCC11 WT (Gly180) would be responsible for the secretion of preodoriferous compounds from the axillary apocrine gland. In primates, axillary odors may play a role in olfactory communication, although no documented behavioral or endocrine changes resulting from volatiles produced in the axillae have been reported to occur in humans. Previous studies have described the presence of androgen steroids in the axillary area. Androsterone sulfate (AS) and DHEAS were detected in an extract of axillary hairs in addition to high levels of cholesterol (Julesz, 1968). It was also demonstrated, following injection of radioactive pregnenolone or progesterone, that steroid secretion was concentrated in the axillary area (Brooksbank, 1970). In those studies, however, the axillary sweat collected from the skin surface contained a mixture of materials from apocrine, eccrine, and sebaceous glands, in addition to desquamating epidermal cells. In this respect, Labows et al. (1979) demonstrated that pure apocrine secretions contained at least two androgen steroids, AS and DHEAS, in addition to cholesterol. It is strongly suggested that 
one of the physiological functions of ABCC11 WT is the active transport of steroid metabolites, such as AS and DHEAS, into the lumen of apocrine glands.

\section{ENDOPLASMIC RETICULUM-ASSOCIATED DEGRADATION OF THE SNP VARIANT OF ABCC11}

Why does one SNP (c.538G > A) in the human ABCC11 gene affect the function of apocrine glands? To address this question, we have recently provided evidence that proteasomal degradation of the SNP variant (Arg180) of ABCC11 is the underlying molecular mechanism (Toyoda etal., 2009). ABCC11 WT with Gly180 is an $\mathrm{N}$-linked glycosylated protein, which is localized within intracellular granules and large vacuoles as well as at the luminal membrane of secretory cells in the cerumen apocrine gland (Toyoda et al., 2009). N-linked glycosylation occurs at both Asn 838 and Asn 844 in the extracellular loop between transmembrane domains 7 (TM7) and 8 (TM8) of the ABCC11 WT protein. In contrast, the SNP variant (Arg180) lacks $N$-linked glycosylation and readily undergoes proteasomal degradation, most probably via ubiquitination. As a consequence, no granular or vacuolar localization was detected in the cerumen apocrine glands of people homozygous for the SNP variant.

Morphological differences were previously reported between the secretory cells of wet and dry types of human ceruminous glands (Shugyo et al., 1988). In the wet-type glands, the Golgi apparatus was reportedly well developed, whereas it was generally small in the corresponding cells of the dry-type. Furthermore, numerous intracellular granules were observed in the wet-type gland in close relationship to their well-developed Golgi apparatus, whereas intracellular granules were rare in the dry-type gland.

The endoplasmic reticulum (ER) and Golgi apparatus are the synthesis and maturation sites of proteins destined for the plasma membrane, the secretory and endocytic organelles, and secretion (Ellgaard et al., 1999; Helenius and Aebi, 2004). Efficient quality control systems have evolved to prevent incompletely folded proteins from moving along the secretory pathway. Accumulation of misfolded proteins in the ER would detrimentally affect cellular functions. Therefore, misfolded proteins may be removed from the ER by retrotranslocation to the cytosol compartment where they are degraded by the ubiquitin-proteasome system. This process is known as ER-associated degradation (ERAD; Mori, 2000; Ellgaard and Helenius, 2001; Hampton, 2002; Kleizen and Braakman, 2004). It is likely that the product of the SNP variant (Arg180) is recognized as a misfolded protein in the ER and readily undergoes proteasomal degradation. An electrostatic charge (either positive or negative) at amino acid 180 in the transmembrane domain 1 (TM1) might interfere with correct folding of the de novo synthesized ABCC11 protein in the ER (Toyoda et al., 2009). This ERAD processing of the SNP variant (Arg180) of ABCC11 may greatly influence the activity of ceruminous apocrine glands and determine the type of human earwax. Similar ERAD processing is considered to take place for the SNP variant (Arg180) of ABCC11 in axillary and mammary apocrine glands. Figure 4 schematically illustrates the impact of this SNP on the cellular localization and function of ABCC11 in secretory cells of the apocrine gland. Asn838 and Asn844 are glycosylation target sites in the human ABCC11. The $N$-linked glycans are thought to be subjected to extensive modification as glycoproteins mature and move through the ER via the Golgi apparatus to their final destinations as, for example, intracellular granules and large vacuoles of secretory cells in the apocrine gland.

\section{ABCC11 WILD-TYPE ALLELE AND BREAST CANCER RISK}

In 1971, Petrakis (1971) first reported that international mortality and frequency rates for breast cancer seemed to be associated with the frequency of the allele for wet-type earwax. Caucasians and African-Americans in the USA as well as Germans exhibited approximately fourfold higher rates of breast cancer mortality as compared with Japanese and Taiwanese women (Petrakis, 1971). Nevertheless, the phenotypic association of the wet-type of earwax with breast cancer remained controversial (Petrakis, 1971; Ing et al., 1973).

At the present time, it is not well understood whether ABCC11 WT really contributes to breast cancer risk. Therefore, we have most recently carried out a genotyping study of the SNP 538G > A (Gly180Arg) for a total of 543 Japanese women to examine the association between the frequency rate of breast cancer and the allelic frequency of the G allele (WT). We obtained blood samples from patients with invasive breast cancer $(n=270)$ and control volunteers $(n=273)$ and genotyped the SNP c.538G $>\mathrm{A}$ in the $A B C C 11$ gene. The frequency of the $538 \mathrm{G}$ allele in the breast cancer patients was higher than that in the control volunteers. The odds ratio for the women with genotypes $(\mathrm{G} / \mathrm{G}+\mathrm{G} / \mathrm{A})$ to develop breast cancer was estimated as 1.63 ( $p$-value $=0.026$ ), suggesting that the $538 \mathrm{G}$ allele in the $A B C C 11$ gene is moderately associated with the risk of breast cancer (Ota et al., 2010). The relative ratio of breast cancer patients carrying the homozygous 538G/G allele was 1.77-fold greater than that of the corresponding healthy volunteers (Ota et al., 2010). This relative ratio was even greater than that (1.41-fold) for breast cancer patients carrying heterozygous alleles 538G/A. The $\mathrm{G}$ allele appears to be positively related to breast cancer frequency in the groups of Japanese women studied. In contrast, no significant association with breast cancer risk was observed in Europeans (Beesley et al., 2011; Lang et al., 2011).

We initially thought that some genetically determined variation(s) in the apocrine system might influence susceptibility to breast cancer, although the genetic determinant $(538 \mathrm{G}>\mathrm{A}$ SNP in $A B C C 11$ ) was not known at that time. It is hypothesized that the function of $\mathrm{ABCC} 11$ per se, or metabolites transported by ABCC11, may stimulate the proliferation of apocrine gland cells to enhance the risk of mastopathy (Figure 5). This hypothesis is supported by evidence that apocrine glands are large in individuals carrying the WT allele of the $A B C C 11$ gene. So far as the cell cycle machinery is operating normally, proliferation of apocrine gland cells should be controlled to a certain extent. When a somatic mutation has occurred in BRCA1, BRCA2, $p 53$, or $p 21$, however, it can lead to deleterious and unregulated proliferation of those cells (Figure 5).

\section{REGULATION OF ABCC11 GENE EXPRESSION}

In 2004, Bieche etal. (2004) reported that ABCC11 was upregulated in estrogen receptor $\alpha$-positive breast tumors, as compared with normal breast tissue. In contrast, Sosonkina et al. (2011) reported down-regulation of ABCC11 protein in human 


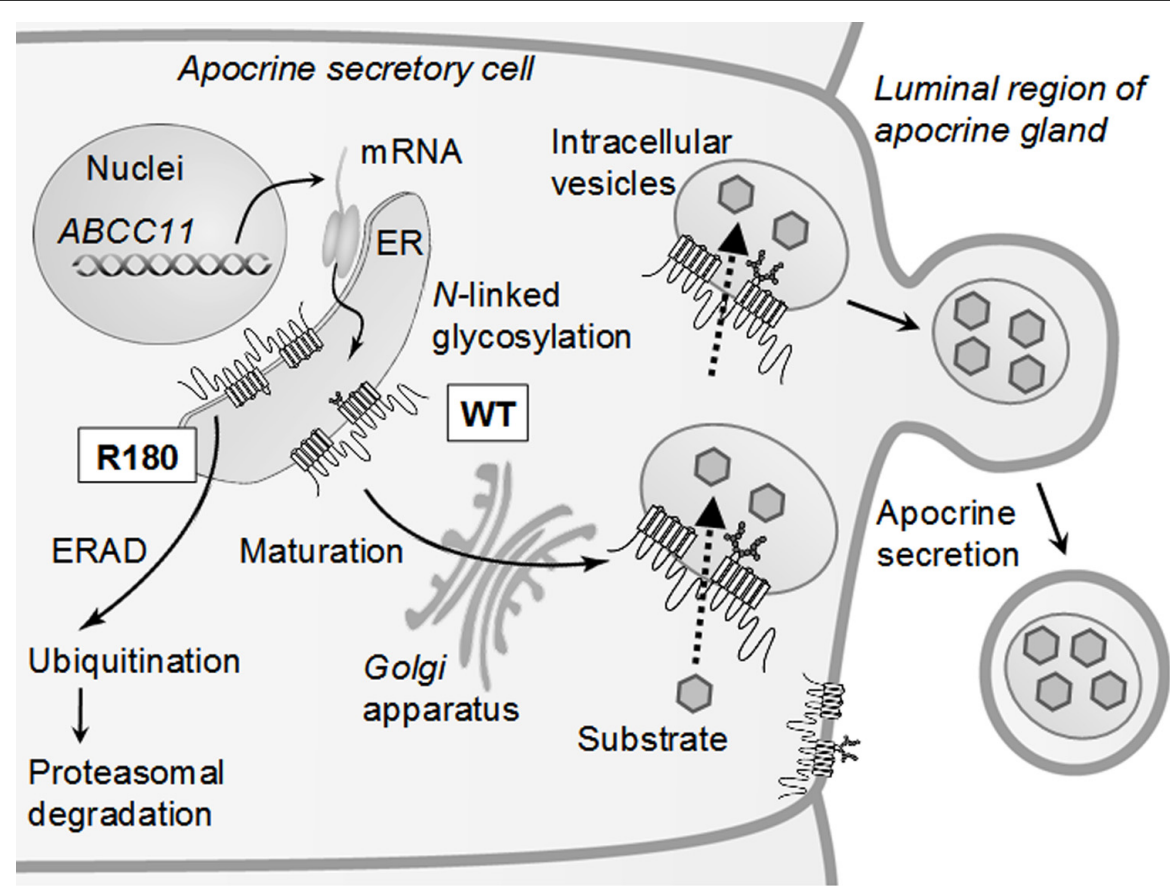

FIGURE 4 | Schematic illustration of intracellular sorting of ABCC11 WT and proteasomal degradation of the R180 (Arg180) variant in secretory cells of the apocrine gland. De novo synthesized ABCC11 WT is $\mathrm{N}$-linked glycosylated at Asn838 and Asn844 in the ER, further processed in the Golgi apparatus, and destined for the membranes of intracellular granules and vacuoles. Ceruminous components are thought to be transported by
ABCC11 WT and sequestered in intracellular granules and vacuoles. SNP variant R180 lacking $N$-linked glycosylation is recognized as a misfolded protein in the ER and readily undergoes ubiquitination and proteasomal degradation (ERAD pathway). ER, endoplasmic reticulum; ERAD, ER-associated degradation. This scheme is modified from Toyoda et al. (2009).

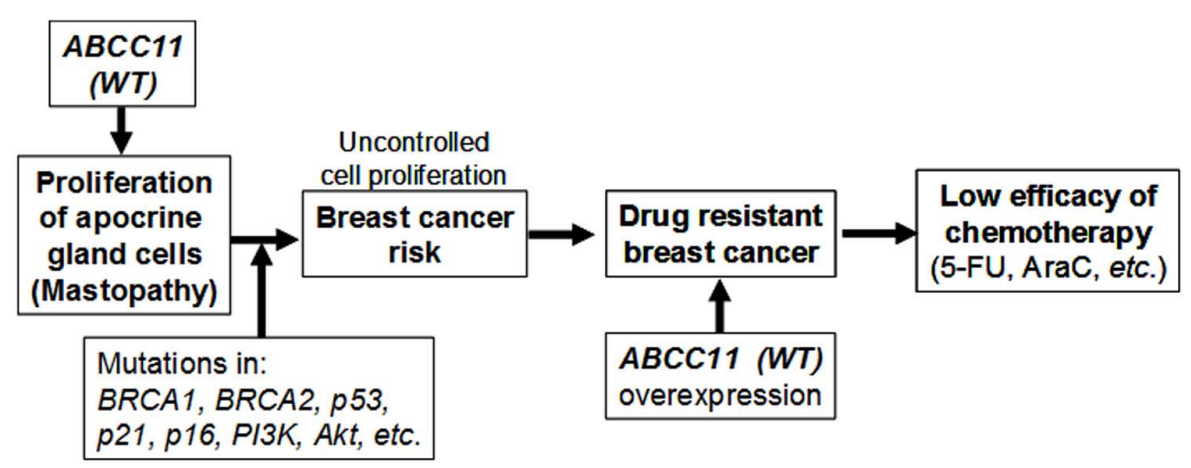

FIGURE 5 | The potential impact of $A B C C 11 W T$ (538G) on the apocrine phenotype, patients' response to nucleoside-based chemotherapy, and the potential risk of mastopathy and breast cancer. BRCA-1, breast cancer-1; BRCA-2, breast cancer-2; PI3K, phosphatidylinositol 3-kinase; ER $\alpha$ $(+)$, estrogen receptor $\alpha$-positive; 5-FU, 5-fluorouracil; AraC, cytarabine. This scheme is modified form Toyoda and Ishikawa (2010). breast cancer. Park et al. (2006) investigated the mRNA levels of $\mathrm{ABC}$ transporter genes in breast cancer patients who underwent sequential weekly paclitaxel/FEC (5-fluorouracil, epirubicin, and cyclophosphamide) neoadjuvant chemotherapy. Their analysis showed that the expression of ABCC11 was increased (fold ratio $=2.71$ ) in those patients with residual disease as compared with the patients having no pathologic evidence of any residual invasive cancer cells in the breast.

Honorat etal. (2008) have demonstrated that endogenous ABCC11 mRNA levels in breast cell lines are correlated with their estrogen receptor $\alpha$-status. Interestingly, they found that ABCC11 expression was reduced in vitro by $\mathrm{E}_{2}$ treatments. Furthermore, this $\mathrm{E}_{2}$-dependent down-regulation of $\mathrm{ABCC} 11$ expression was blocked by co-treatment with tamoxifen, an $\mathrm{E}_{2}$ antagonist. These findings suggest that $\mathrm{ABCC} 11$ expression is regulated directly or indirectly by estrogen receptor $\alpha$ and that the prolonged exposure of breast cancer cells to tamoxifen can lead to up-regulation of ABCC11.

Hauswald etal. (2009) have shown that some of the histone deacetylase inhibitors induced the expression of several $\mathrm{ABC}$ 
transporters, including the $A B C C 11$ gene, to render acute myeloid leukemia cells resistant to a broad-spectrum of drugs. Molecular mechanisms underlying the induction remain to be elucidated. Since histone deacetylase inhibitors can be utilized in combination with conventional anti-cancer drugs in clinical trials, such induction of the ABCC11 WT may affect the efficacy of nucleoside-based chemotherapy.

\section{RELEVANCE OF ABCC11 WT TO DRUG RESISTANCE IN CANCER CHEMOTHERAPY}

The potential involvement of $\mathrm{ABCC} 11$ in drug resistance of breast cancer has recently been reported. For example, ABCC11 mRNA is found to be highly expressed in breast tumors (Bera et al., 2001; Yabuuchi etal., 2001; Bieche etal., 2004), and particularly in invasive ductal adenocarcinomas (available at: https://www.oncomine.org/resource/logn.html, accessed October $01,2012)$. This expression is reportedly regulated by estrogen receptor- $\beta$ (Honorat et al., 2008) and induced by 5 -fluorouracil (5-FU; Oguri et al., 2007). Furthermore, it has been shown that ABCC11 is directly involved in 5-FU resistance by means of the efflux transport of the active metabolite 5-fluoro-2' -deoxyuridine 5'-monophosphate (FdUMP; Guo et al., 2003; Kruh et al., 2007; Oguri et al., 2007). It remains to be elucidated whether the expression of ABCC11 WT (538G) is related to drug resistance of breast cancer and high rates of mortality. Further clinical studies, including protein expression studies in tumors, will be needed to clarify the potential contribution of ABCC11 to breast cancer risk and prognosis, including drug resistance and chemosensitivity.

Because of their structural similarities, it could be anticipated that substrate specificity of ABCC11 would be related to those of ABCC4 and ABCC5. This indeed has been the case. Ectopic expression of ABCC11 in mammalian cells enhances the cellular efflux of cyclic nucleotides and confers resistance to certain anticancer and antiviral nucleotide analogs (Guo et al., 2003). In fact, it has been reported that ABCC11 WT has an ability to efflux cyclic nucleotides (e.g., cGMP and cAMP) and confers resistance to several antiviral and anticancer nucleotide analogs, such as $5^{\prime}$ FdUMP and $9^{\prime}$ - (2' - phosohonylmethoxynyl)adenine (PMEA; Guo et al., 2003; Kruh et al., 2007; Oguri et al., 2007).

Therapy with nucleoside-derived drugs is characterized by inter-individual variability (Heinemann et al., 1988; Abbruzzese et al., 1991). Genetic variants that affect protein products involved in all steps leading to a drug's action may be major contributors to this heterogeneity of responses to nucleoside-based treatments. In particular, variants of drug metabolizing enzymes and transporters might affect the amount of drug needed for an efficient therapeutic response (Errasti-Murugarren and PastorAnglada, 2010).

Successful treatment of cancer remains a therapeutic challenge, with a high percentage of patients suffering from drug resistance or relapsed disease. One of such examples involves anti-leukemia treatment with nucleoside analogs, such as cytarabine (AraC). Guo et al. (2009) have recently presented evidence that expression of ABCC11 WT is an important factor affecting acute myeloid leukemia patient survival. It is very likely that the cause of treatment failure in those patients with high expression of ABCC11
WT is an increased extrusion of AraC from blast cells mediated by the transporter.

Uemura et al. (2010) have recently found that both gene and protein expression of ABCC11 were higher in pemetrexed (MTA)resistant cells than in the parental cells. The MTA-resistant cells showed cross-resistance to MTX, which is a substrate for ABCC11, and intracellular MTX accumulation in MTA-resistant cells was lower than that in the parental cells. They then tested the effect of decreasing the expression of ABCC11 by siRNA and found that decreased expression of ABCC11 enhanced MTA cytotoxicity and increased intracellular MTX accumulation in MTA-resistant cells. These findings suggest that ABCC11 confers resistance to MTA by enhancing the efflux of the intracellular anti-cancer drug.

They further analyzed the relationship between the ABCC11 gene expression and MTA sensitivity of 13 adenocarcinoma cell lines. In contrast to their expectation, there was no correlation. Instead, the 13 lung adenocarcinoma cell lines could be classified into three groups based on the genotypes of the ABCC11 SNP (538G > A); G/G, G/A, and A/A. The A/A group showed a significant reduction in the $\mathrm{IC}_{50}$ value of MTA compared with those values for the combined $\mathrm{G} / \mathrm{G}$ and $\mathrm{G} / \mathrm{A}$ groups, indicating that $A B C C 11538 \mathrm{G}>\mathrm{A}$ is an important determinant of MTA sensitivity. These results suggest that $A B C C 11538 \mathrm{G}>\mathrm{A}$ may be one of the biomarkers for selection of MTA treatment in adenocarcinomas. This finding, however, should be carefully evaluated by clinical studies to determine whether ABCC11 538G > A is truly a clinically important biomarker for the prediction of chemotherapeutic efficacy.

\section{CONCLUSION}

Apocrine secretion occurs when the secretory process is accomplished with a partial loss of cell cytoplasm. The secretory materials may be contained within the secretory vesicles or dissolved in the cytoplasm and then released during excretion as cytoplasmic fragments into the glandular lumen or interstitial space (Gesase and Satoh, 2003). Hitherto, apocrine secretory mechanisms have not been well characterized (Gesase and Satoh, 2003). Although the biochemical and physiological pathways that regulate the apocrine secretory process are not clearly known, our recent findings (Yoshiura et al., 2006; Toyoda et al., 2009; Inoue et al., 2010) that the SNP (538G > A, Gly180Arg) in the ABCC11 gene determines both earwax type and axillary osmidrosis have shed light on the novel function of this ABC transporter in apocrine glands. Further studies are needed to explore the clinical significance of ABCC11 so as to elucidate whether there are any other diseases that involve apocrine secretion.

\section{ACKNOWLEDGMENTS}

The authors' studies were supported in part by CREST from the Japan Science and Technology Agency (JST) and Grants-in-Aid for Scientific Research (Category S, No. 13854024; and Priority Area "Applied Genomics" No. 17019055) from the Ministry of Education, Culture, Sports, Science and Technology of Japan (to Norio Niikawa) as well as by the JST research project "Development of the world's fastest SNP detection system" (to Toshihisa Ishikawa). Yu Toyoda is a research fellow of the Japanese Society for Promotion of Science (JSPS). 


\section{REFERENCES}

Abbruzzese, J. L., Grunewald, R., Weeks, E. A., Gravel, D., Adams, T., Nowak, B., etal. (1991). A phase I clinical, plasma, and cellular pharmacology study of gemcitabine. J. Clin. Oncol. 9, 491-498.

Beesley, J., Johnatty, S. E., Chen, X., Spurdle, A. B., Peterlongo, P., Barile, M., et al. (2011). No evidence for an association between the earwaxassociated polymorphism in ABCC11 and breast cancer risk in Caucasian women. Breast Cancer Res. Treat. 126, 235-239.

Bera, T. K., Lee, S., Salvatore, G, Lee, B., and Pastan, I. (2001). MRP8, a new member of ABC transporter superfamily, identified by EST database mining and gene prediction program, is highly expressed in breast cancer. Mol. Med. 7, 509-516.

Bieche, I., Girault, I., Urbain, E., Tozlu, S., and Lidereau, R. (2004). Relationship between intratumoral expression of genes coding for xenobiotic-metabolizing enzymes and benefit from adjuvant tamoxifen in estrogen receptor alphapositive postmenopausal breast carcinoma. Breast Cancer Res. 6, R252-R263.

Bonatto, S. L., and Salzano, F. M. (1997). A single and early migration for the peopling of the Americas supported by mitochondrial DNA sequence data. Proc. Natl. Acad. Sci. U.S.A. 94, 1866-1871.

Borst, P., and Elferink, R. O. (2002). Mammalian $\mathrm{ABC}$ transporters in health and disease. Annu. Rev. Biochem. 71, 537-592.

Bortfeld, M., Rius, M., Konig, J., HeroldMende, C., Nies, A. T., and Keppler, D. (2006). Human multidrug resistance protein 8 (MRP8/ABCC11), an apical efflux pump for steroid sulfates, is an axonal protein of the CNS and peripheral nervous system. Neuroscience 137, 12471257.

Bowler, J. M., Johnston, H., Olley, J. M., Prescott, J. R., Roberts, R. G., Shawcross, W., et al. (2003). New ages for human occupation and climatic change at Lake Mungo, Australia. Nature 421, 837-840.

Brooksbank, B. W. (1970). Labelling of steroids in axillary sweat after administration of 3H-delta-5pregnenolone and 14C-progesterone to a healthy man. Experientia 26, 1012-1014.

Cavalli-Sforza, L. L. (2005). The human genome diversity project: past, present and future. Nat. Rev. Genet. 6, 333-340.
Chen, Z. S., Guo, Y., Belinsky, M. G., Kotova, E., and Kruh, G. D. (2005). Transport of bile acids, sulfated steroids, estradiol 17-beta-Dglucuronide, and leukotriene $\mathrm{C}_{4}$ by human multidrug resistance protein 8 (ABCC11). Mol. Pharmacol. 67, 545-557.

Dean, M., Rzhetsky, A., and Allikmets, R. (2001). The human ATP-binding cassette (ABC) transporter superfamily. Genome Res. 11, 1156-1166.

Dillehay, T. D. (2003). Tracking the first Americans. Nature 425, 23-24.

Ellgaard, L., and Helenius, A. (2001). ER quality control: towards an understanding at the molecular level. Curr. Opin. Cell Biol. 13, 431-437.

Ellgaard, L., Molinari, M., and Helenius, A. (1999). Setting the standards: quality control in the secretory pathway. Science 286, 1882-1888.

Errasti-Murugarren, E., and PastorAnglada, M. (2010). Drug transporter pharmacogenetics in nucleosidebased therapies. Pharmacogenomics 11, 809-841.

Gesase, A. P., and Satoh, Y. (2003). Apocrine secretory mechanism: recent findings and unresolved problems. Histol. Histopathol. 18, 597-608.

Goedde, H. W., Agarwal, D. P., Fritze, G., Meier-Tackmann, D., Singh, S., Beckmann, G., et al. (1992). Distribution of $\mathrm{ADH} 2$ and ALDH2 genotypes in different populations. Hum. Genet. 88, 344-346.

Gonzáles-José, R., Gonzáles-Martin, A., Hernández, M., Pucclarell, H. M., Sardi, M., Rosales, A., et al. (2003). Craniometric evidence for Palaeoamerican survival in Baja California. Nature 425, 62-65.

Guo, Y., Kock, K., Ritter, C. A., Chen, Z. S., Grube, M., Jedlitschky, G., et al. (2009). Expression of ABCC-type nucleotide exporters in blasts of adult acute myeloid leukemia: relation to long-term survival. Clin. Cancer Res. 15, 1762-1769.

Guo, Y., Kotova, E., Chen, Z. S., Lee, K., Hopper-Borge, E., Belinsky, M. G., et al. (2003). MRP8, ATP-binding cassette C11 (ABCC11), is a cyclic nucleotide efflux pump and a resistance factor for fluoropyrimidines $2^{\prime}, 3^{\prime}$-dideoxycytidine and $9^{\prime}-\left(2^{\prime}-\right.$ phosphonylmethoxyethyl)adenine. $J$. Biol. Chem. 278, 29509-29514.

Hampton, R. Y. (2002). ER-associated degradation in protein quality control and cellular regulation. Curr. Opin. Cell Biol. 14, 476-482.

Hauswald, S., Duque-Afonso, J., Wagner, M. M., Schertl, F. M., Lubbert, M., Peschel, C., et al. (2009). Histone deacetylase inhibitors induce a very broad, pleiotropic anticancer drug resistance phenotype in acute myeloid leukemia cells by modulation of multiple $\mathrm{ABC}$ transporter genes. Clin. Cancer Res. 15, 37053715 .

Heinemann, V., Hertel, L. W., Grindey, G. B., and Plunkett, W. (1988). Comparison of the cellular pharmacokinetics and toxicity of $2^{\prime}, 2^{\prime}$-difluorodeoxycytidine and 1-beta-D-arabinofuranosylcytosine. Cancer Res. 48, 4024-4031.

Helenius, A., and Aebi, M. (2004). Roles of $N$-linked glycans in the endoplasmic reticulum. Annu. Rev. Biochem. 73, 1019-1049.

Hess J., Lonergan, I., Rozzelle, A. A., and Arneja, J. S. (2008). Axillary osmidrosis in Apert syndrome: management with an arthroscopic shaver technique. J. Craniofac. Surg. 19, 1126-1130.

Holland, I. B., Cole, S. P. C., Kuchler, K., and Higgins, C. F. (2003). ABC Proteins: From Bacteria to Man. Amsterdam: Academic Press.

Honorat, M., Mesnier, A., Vendrell, J., Guitton, J., Bieche, I., Lidereau, R., etal. (2008). ABCC11 expression is regulated by estrogen in MCF7 cells, correlated with estrogen receptor alpha expression in postmenopausal breast tumors and overexpressed in tamoxifen-resistant breast cancer cells. Endocr. Relat. Cancer 15, 125-138.

Horai, S., Kondo, R., Murayama, K. Hayashi, S., Koike, H., and Nakai, N. (1991). Phylogenetic affiliation of ancient and contemporary human inferred from mitochondrial DNA. Philos. Trans. R. Soc. Lond. B Biol. Sci. 333, 409-417.

Horai, S., Kondo, R., Nakagawa-Hattori, Y., Hayashi, S., Sonoda, S., and Tajima, K. (1993). Peopling of the Americas, founded by four major lineages of mitochondrial DNA. Mol. Biol. Evol. 10, 23-47.

Iizuka, M., and Nakahashi, T. (2002). A population genetic study on the transition from Jomon people to Yayoi people. Genes Genet. Syst. 77, 287-300.

Ing, R., Petrakis, L., and Ho, H. C. (1973). Evidence against association between wet cerumen and breast cancer. Lancet 1, 41

Inoue, Y., Mori, T., Toyoda, Y., Sakurai, A., Ishikawa, T., Mitani, Y. etal. (2010). Correlation of axillary osmidrosis to a SNP in the ABCC11 gene determined by the Smart Amplification Process (SmartAmp) method. J. Plast. Reconstr. Aesthet. Surg. 63, 1369 1374.
Ishikawa, T. (2003). "Multidrug resistance: genomics of ABC transporters," in Nature Encyclopedia of the Human Genome, Vol. 4, ed. D. N. Cooper (London: Nature Publishing Group), 154-160.

Ishikawa, T., and Hayashizaki, Y. (2012). Clinical SNP detection by SmartAmp method. Methods Mol. Biol. (in press).

Julesz, M. (1968). New advances in the field of androgenic steroidogenesis of the human skin. Acta Med. Acad. Sci. Hung. 25, 273-285.

Klein, I., Sarkadi, B., and Váradi, A. (1999). An inventory of the human ABC proteins. Biochim. Biophys. Acta 1461, 237-262.

Kleizen, B., and Braakman, I. (2004). Protein folding and quality control in the endoplasmic reticulum. Curr. Opin. Cell Biol. 16, 343-349.

Kruh, G. D., Guo, Y., Hopper-Borge, E., Belinsky, M. G., and Chen, Z. S. (2007). ABCC10, ABCC11, and ABCC12. Pflugers Arch. 453, 675-684.

Labows, J. N., Preti, G., Hoelzle, E., Leyden, J., and Kligman, A. (1979). Steroid analysis of human apocrine secretion. Steroids 34, 249-258.

Lang, T., Justenhoven, C., Winter, S., Baisch, C., Hamann, U., Harth, V., et al. (2011). The earwax-associated SNP c. 538G > A (G180R) in ABCC11 is not associated with breast cancer risk in Europeans. Breast Cancer Res. Treat. 129, 993-999.

Luo, H. R., Wu, G. S., Pakstis, A. J., Tong, L., Oota, H., Kidd, K. K., and Zhang, Y. P. (2009). Origin and dispersal of atypical aldehyde dehydrogenase ALDH2487Lys. Gene 435, 96-103.

Martin, A., Saathoff, M., Kuhn, F., Max, H., Terstegen, L., and Natsch, A. (2010). A functional ABCC11 allele is essential in the biochemical formation of human axillary odor. J. Invest. Dermatol. 130, 529-540.

Matsunaga, E. (1962). The dimorphism in human normal cerumen. Ann. Hum. Genet. 25, 273-286.

Miura, K., Yoshiura, K., Miura, S., Shimada, T., Yamasaki, K., Yoshida, A., etal. (2007). A strong association between human earwax-type and apocrine colostrum secretion from the mammary gland. Hum. Genet. 121, 631-633.

Mori, K. (2000). Tripartite management of unfolded proteins in the endoplasmic reticulum. Cell 101, 451-454.

Nakano, M., Miwa, N., Hirano, A., Yoshiura, K., and Niikawa, N. (2009). A strong association of axillary osmidrosis with the wet earwax type determined by genotyping of the 
ABCC11 gene. BMC Genet. 10:42. doi: 10.1186/1471-2156-10-42

Nei, M. (1982). Evolution of human races at the gene level. Prog. Clin. Biol. Res. 103(Pt A), 167-181.

Oguri, T., Bessho, Y., Achiwa, H., Ozasa, H., Maeno, K., Maeda, H., et al. (2007). MRP8/ABCC11 directly confers resistance to 5-fluorouracil. $\mathrm{Mol}$. Cancer Ther. 6, 122-127.

Ohashi, J., Naka, I., and Tsuchiya, N. (2011). The impact of natural selection on the ABCC11 SNP determining earwax type. Mol. Biol. Evol. 28, 849-857.

Ono, N., van der Heiden, I., Schffer, G. L., van de Wetering, K., van Deenter, E., de Haas, M., et al. (2007). Multidrug resistance-associated protein 9 (ABCC12) is present in sperm. Biochem. J. 406, 31-40.

Ota, I., Sakurai, A., Toyoda, Y., Morita, A., Sasaki, T., Chishima, T., et al. (2010). Association between breast cancer risk and the wild-type allele of human ABC transporter ABCC11. Anticancer Res. 30, 5189-5194.

Park, S., Shimizu, C., Shimoyama, T., Takeda, M., Ando, M., Kohno, T., et al. (2006). Gene expression profiling of ATP-binding cassette (ABC) transporters as a predictor of the pathologic response to neoadjuvant chemotherapy in breast cancer patients. Breast Cancer Res. Treat. 99, 9-17.

Petrakis, N. L. (1971). Cerumen genetics and human breast cancer. Science 173, 347-349.

Roychoudhury, A., and Nei, M. (1988). Human Polymorphic Gene: World Distribution. Oxford: Oxford University Press.

Saitou, N., and Nei, M. (1987). The neighbor-joining method: a new method for reconstructing phylogenetic trees. Mol. Biol. Evol. 4, 406-425.

Sakurai, A., Onishi, Y., Hirano, H., Seigneuret, M., Obanayama, K., Kim, G., etal. (2007). Quantitative structure-activity relationship analysis and molecular dynamics simulation to functionally validate nonsynonymous polymorphisms of human ABC transporter ABCB1 ( $P$ glycoprotein/MDR1). Biochemistry 46, 7678-7693.

Schinkel, A. H., and Jonker, J. W. (2003) Mammalian drug efflux transporters of the ATP binding cassette (ABC) family: an overview. Adv. Drug Deliv. Rev. 55, 3-29.

Shehadeh, N. H., and Kligman, A. M. (1963). The effect of topical antibacterial agents on the bacterial flora of the axilla. J. Invest. Dermatol. 40 61-71.

Shimizu, H., Taniguchi, H., Hippo, Y, Hayashizaki, Y., Aburatani, H., and Ishikawa, T. (2003). Characterization of the mouse Abccl2 gene and its transcript encoding an ATP-binding cassette transporter, an orthologue of human ABCC12. Gene 310, 17-28.

Shugyo, Y., Sudo, N., Kanai, K. Yamashita, T., Kumazawa, T., and Kanamura, S. (1988). Morphological differences between secretory cells of wet and dry types of human ceruminous glands. Am. J. Anat. 181, 377-384.

Sosonkina, N., Nakashima, M., Ohta, T., Niikawa, N., and Starenki, D. (2011). Down-regulation of $\mathrm{ABCC} 11$ protein (MRP8) in human breast cancer. Exp. Oncol. 33, 42-46.

Spitsyn, V. A., and Afanasèva, I. (1989). Genetic geography of inherited dimorphism of ear wax by its consistency. Genetika (Russian) 25, 1854-1860.

Super Science High School Consortium. (2009). Japanese map of the earwax gene frequency: a nationwide collaborative study by Super Science High School Consortium. J. Hum. Genet. 54, 499-503.

Tajima, A., Hayami, M., Tokunaga, K. Juji, T., Matsuo, M., Marzuki, S., et al. (2004). Genetic origins of the Ainu inferred from combined DNA analyses of maternal and paternal lineages. J. Hum. Genet. 49, 187-193.

Tammur, J., Prades, C., Arnould, I., Rzhetsky, A., Hutchinson, A., Adachi, M., et al. (2001). Two new genes from the human ATP-binding cassette transporter superfamily, ABCC11 and $\mathrm{ABCC} 12$, tandemly duplicated on chromosome 16q12. Gene 273, 89-96.

Temple, D. H., Auerbach, B. M., Nakatsukasa, M., Sciulli, P. W., and Larsen, C. S. (2008). Variation in limb proportions between Jomon foragers and Yayoi agriculturalists from prehistoric Japan. Am. J. Phys. Anthropol. 137, 164-174.

Temple, D. H. (2010). Patterns of systemic stress during the agricultural transition in prehistoric Japan. Am J. Phys. Anthropol. 142, 112-124.

The HUGO Pan-Asian SNP Consortium. (2009). Mapping human Genetic diversity in Asia. Science 326, 1541-1545.

Tokunaga, K., Ohashi, J., Bannai, M. and Juji, T. (2001). Genetic link between Asians and native Americans: Evidence from HLA genes and haplotypes. Hum. Immunol. 62 , 1001-1008.

Toyoda, Y., Hagiya, Y., Adachi, T., Hoshijima, K., Kuo, M. T., and Ishikawa, T. (2008). MRP class of human ATP binding cassette (ABC) transporters: historical background and new research directions. Xenobiotica 38, 833-862.

Toyoda, Y., Sakurai, A., Mitani, Y., Nakashima, M., Yoshiura, K., Nakagawa, H., et al. (2009). Earwax, osmidrosis, and breast cancer: why does one SNP $(538 \mathrm{G}>\mathrm{A})$ in the human $\mathrm{ABC}$ transporter ABCC11 gene determine earwax type? FASEB J. 23, 2001-2013.

Toyoda, Y., and Ishikawa, T. (2010). Pharmacogenomics of human $\mathrm{ABC}$ transporter ABCC11 (MRP8): potential risk of breast cancer and chemotherapy failure. Anticancer Agents Med. Chem. 10, 617-624.

Uemura, T., Oguri, T., Ozasa, H., Takakuwa, O., Miyazaki, M., Maeno, K., et al. (2010). ABCC11/MRP8 confers pemetrexed resistance in lung cancer. Cancer Sci. 101, 2404-2410.

Wu, W. H., Ma, S., Lin, J. T., Tang, Y. W., Fang, R. H., and Yeh, F. L. (1994). Surgical treatment of axillary osmidrosis: an analysis of 343 cases. Plast. Reconstr. Surg. 94 288-294.
Yabuuchi, H., Shimizu, H., Takayanagi, S., and Ishikawa, T. (2001). Multiple splicing variants of two new human ATP-binding cassette transporters, ABCC11 and ABCC12. Biochem. Biophys. Res. Commun. 288, 933-939.

Yoo, W. M., Pae, N. S., Lee, S. J., Roh, T. S., Chung, S., and Tark, K. C. (2006). Endoscopy-assisted ultrasonic surgical aspiration of axillary osmidrosis: a retrospective review of 896 consecutive patients from 1998 to 2004. J. Plast. Reconstr. Aesthet. Surg. 59, 978-982.

Yoshiura, K., Kinoshita, A., Ishida, T., Ninokata, A., Ishikawa, T., Kaname, T., etal. (2006). A SNP in the ABCC11 gene is the determinant of human earwax type. Nat. Genet. 38, 324-330.

Conflict of Interest Statement: The authors declare that the research was conducted in the absence of any commercial or financial relationships that could be construed as a potential conflict of interest.

Received: 15 October 2012; accepted: 11 December 2012; published online: 02 January 2013.

Citation: Ishikawa T, Toyoda Y, Yoshiura $K-i$ and Niikawa $N$ (2013) Pharmacogenetics of human $A B C$ transporter ABCC11: new insights into apocrine gland growth and metabolite secretion. Front. Gene. 3:306. doi: 10.3389/fgene. 2012.00306

This article was submitted to Frontiers in Pharmacogenetics and Pharmacogenomics, a specialty of Frontiers in Genetics.

Copyright (C) 2013 Ishikawa, Toyoda, Yoshiura and Niikawa. This is an openaccess article distributed under the terms of the Creative Commons Attribution License, which permits use, distribution and reproduction in other forums, provided the original authors and source are credited and subject to any copyright notices concerning any third-party graphics etc. 


\section{APPENDIX}

\section{CLINICAL GENOTYPING OF SNP 538G > A (Gly180Arg) IN THE ABCC11 GENE}

The rapid growth of personalized medicine is being supported by emerging new technologies together with accumulating knowledge of pharmacogenomics. We tried to create a clinical method, the SmartAmp, to genotype the SNP 538G > A in the human ABCC11 gene. The SmartAmp-based method enables us to detect genetic polymorphisms or mutations in about 30 min under isothermal conditions without requiring DNA isolation and PCR processes for sample preparation (Ishikawa and Hayashizaki, 2012). Figure A2A schematically illustrates the strategy of SNP detection by this clinical method. To determine the SNP 538G > A (Gly180Arg) in the $A B C C 11$ gene, we prepared one set of primers designated TP, FP, BP, OP, and CP (Figure A2A). The TPS discriminate the polymorphism 538G or 538A in the ABCC11 gene, and the CPS inhibit the background amplification from mismatch sequence pairs (Toyoda et al., 2009; Ishikawa and Hayashizaki, 2012). These primers selectively recognized the SNP 538G > A of the ABCC11 gene to discriminate homozygous 538G/G, heterozygous 538G/A, and homozygous 538A/A (Figure A2A). Thus, this genotyping method would provide a practical tool to support clinical diagnosis (Ishikawa and Hayashizaki, 2012).<smiles>Nc1nc2c(ncn2C2CC3CCCC2OP(=O)([O-])O3)c(=O)[nH]1</smiles>

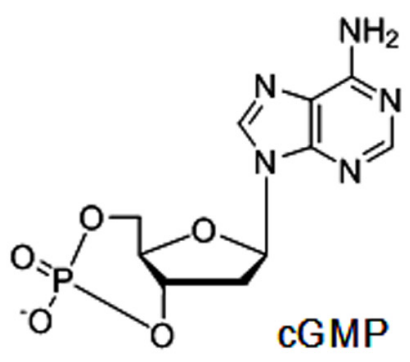<smiles>CCCCC/C=C\C/C=C\C=C\C=C\[C@@H](SC[C@H](NC(=O)CC[C@H](N)C(=O)O)C(=O)NCC(=O)O)C(C)CCCC(=O)O</smiles><smiles>N[C@@H](CCC(=O)N[C@@H](CSc1ccc([N+](=O)[O-])cc1[N+](=O)[O-])C(=O)NCC(=O)O)C(=O)O</smiles><smiles>O=C1CC[C@@H]2C1CC[C@@H]1c3ccc(OS(=O)(=O)O)cc3CCC12</smiles><smiles>C[C@]12CCC3C(CC=C4C[C@@H](OS(=O)(=O)O)CC[C@]43C)C1CCC2=O</smiles><smiles>C[C@H](CCC(=O)NCCS(=O)(=O)O)[C@H]1CC[C@H]2[C@H]3[C@H](C[C@H](O)[C@@]21C)[C@@]1(C)CC[C@H](O)C[C@H]1C[C@H]3O</smiles>

Taurocholic acid

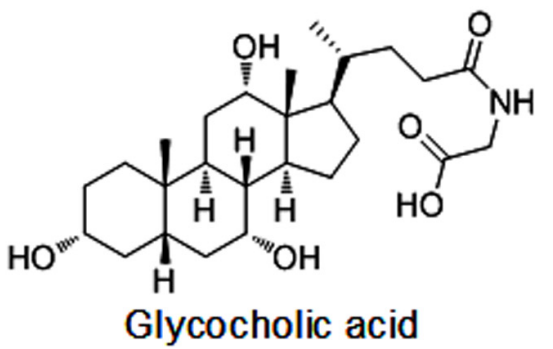

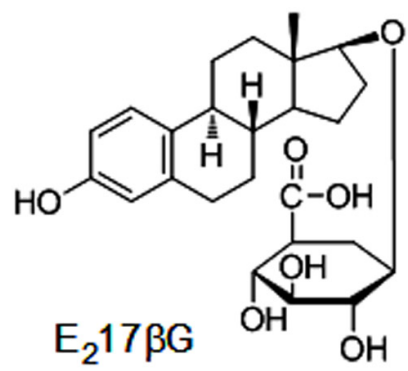

FIGURE A1 | Chemical structures of ABCC11 substrates. Cyclic adenosine monophosphate (cAMP), cyclic guanosine monophosphate (cGMP), leukotriene $\mathrm{C}_{4}\left(\mathrm{LTC}_{4}\right), \mathrm{S}-\left(2,4\right.$-dinitrophenyl)-glutathione (DNP-SG), estrone 3-sulfate $\left(\mathrm{E}_{1} 3 \mathrm{~S}\right)$, dehydroepiandrosterone 3-sulfate (DHEAS), and $\mathrm{E}_{2}$ 17 $\beta \mathrm{GG}$ (estradiol 17- $\beta$-Dglucuronide). 


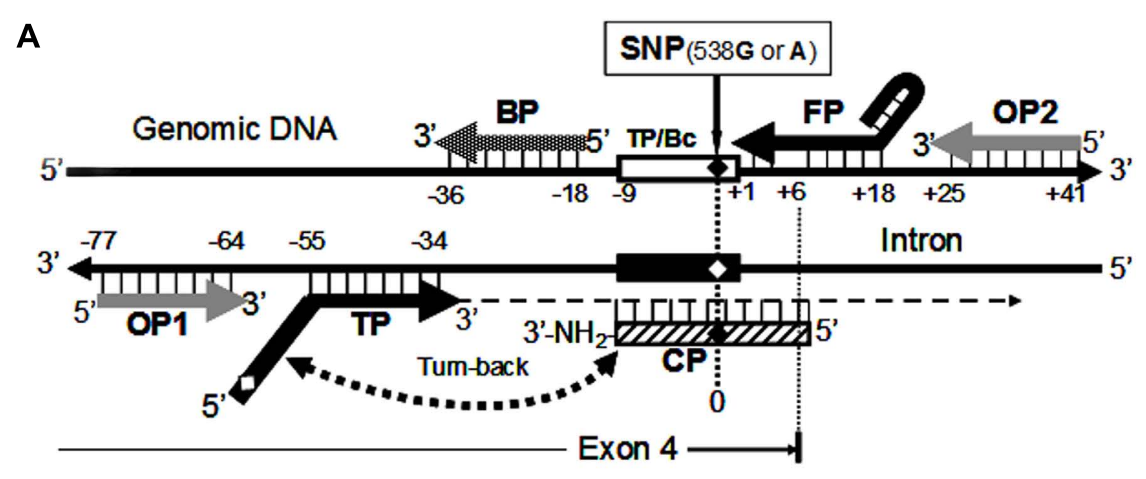

\begin{tabular}{|ll|}
\hline TP (538G) & 5'-CGAGTACACT GGTTGATTTTCGATGCACTTC-3' \\
TP (538A) & 5'- CTGAGTACACT AGGTTGATTTTCGATGCACTTC-3' \\
FP & 5'- agcgatgcgttcgagcatcgct GTCTGCCACTTACTGGCC-3' \\
BP & 5'- AGAAGCAGATGCCCAGAA-3' \\
OP1 & 5'- TGATGCTGAGGTTCCAG-3' \\
OP2 & 5'- TAGAGTCCCCCAAACCT-3' \\
CP (538G) & 5'- TACTGGCTCGAGTACAC-NH ${ }_{2}-3^{\prime}$ \\
CP (538A) & 5'- TACTGGCCCGAGTACAC-NH ${ }_{2}$-3' $^{\prime}$ \\
\hline
\end{tabular}

B
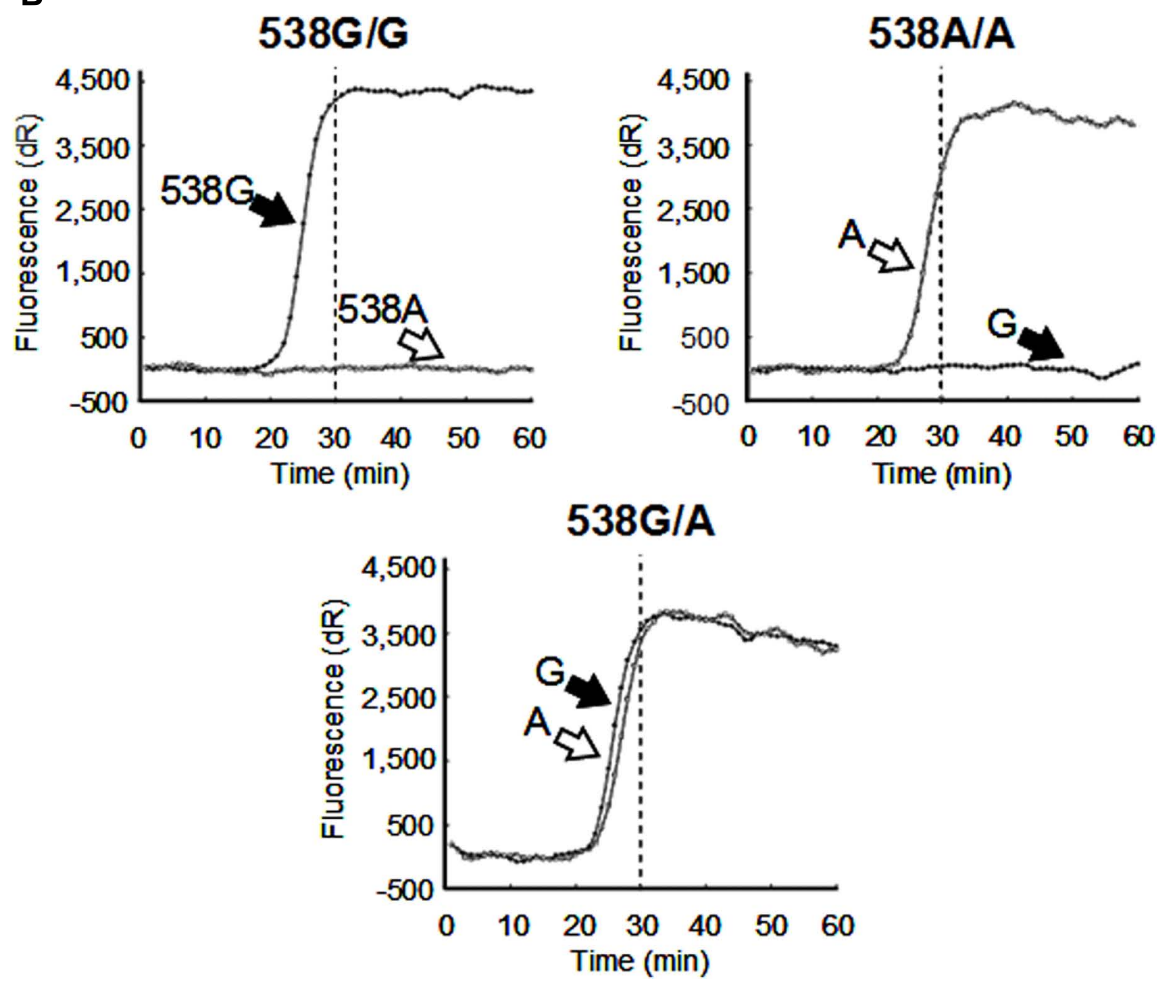

FIGURE A2 | Detection of SNP 538G > A in ABCC11 gene. (A) Strategy and primers for the SmartAmp-based detection of SNP 538G > A residing in exon 4 of the $A B C C 11$ gene on chromosome 16q12 (upper panel) and the sequences of ABCC11 allele-specific primers needed for the SNP detection (lower panel). Arrows indicated the sequence difference between the WT and SNP alleles. (B) Time-courses of the SNPdetection reaction with $\mathrm{ABCC} 11$ allele-specific primers. Data are from Toyoda et al. (2009). 